\title{
Проектирование беспроводных чипсетов 5G для беспилотных автомобилей
}

\author{
Д. Мак-Грат ${ }^{1}$
}

УДК 621.3:629.3 | ВАК 05.27.01

\begin{abstract}
Вероятно, самым большим препятствием на пути широкого распространения беспилотных автомобилей является неприятие инноваций потребителями. Многочисленные исследования показывают, что беспилотные автомобили значительно реже попадают в дорожно-транспортные происшествия, чем их более опытные соперники - люди. Тем не менее, водители не спешат выпускать из рук руль и не хотят превращаться в пассажиров, полностью зависящих от машины. Возможно, со временем эта ситуация изменится - по мере того, как беспилотные автомобили будут совершенствоваться и люди начнут к ним привыкать, потребители, вероятно, будут настроены менее скептически. Ну, а пока проблема озабоченности водителей своей безопасностью стоит очень остро.
\end{abstract}

огласно исследованию, проведенному Американской автомобильной ассоциацией в 2018 году [1] , 73\% американскихводителей заявило, что они побоялись бы ехать в полностью беспилотном автомобиле, а 63\% взрослых жителей США заявили, что они ощущали бы себя менее защищенными во время ходьбы или езды на велосипеде, если бы по дорогам перемещались беспилотные автомобили.

Такое восприятие беспилотных автомобилей - рациональное или нет - показывает, с чем приходится сталкиваться их разработчикам. Озабоченность потребителей безопасностью беспилотных автомобилей вынуждает рассматривать все аспекты беспилотного вождения буквально под микроскопом - от чипсетов и компонентов до серийного производства готовых автомобилей. Столь повышенное внимание потребителей к безопасности беспилотныхавтомобилей подчеркивает важность соответствующего тестирования на всех этапах их проектирования и производства.

\section{БЕЗ ТЕХНОЛОГИЙ 5С НЕ ОБОЙТИСЬ}

Ассоциация инженеров автомобилестроения определяет шесть уровней автоматизации автомобилей [2]: от 0 (отсутствие автоматизации) до 5 (полная автоматизация). Автомобили уровня 5 - полностью беспилотные - не будут требовать никакого вмешательства человека, кроме указания точки назначения. У таких автомобилей не будет руля и педали тормоза.

Автомобилям уровня 5 не обойтись без технологий 5G, которые используются в них для сверхбыстрого и надежного взаимодействия с другими автомобилями, дорожной инфраструктурой, пешеходами и велосипедистами, а такжес облачными ресурсами для получения информации о трафике

Компания Keysight Technologies, главный менеджер по промышленным решениям. и погодных условиях. Беспилотным автомобилям нужны самые передовые технологии и приборы, которые помогут им видеть дорогу и реагировать на изменяющуюся ситуацию. Эти технологии включают радар, лидар, искусственный интеллект и расширенную систему датчиков. Данные, собираемые этими системами, помогают автомобилям безопасно перемещаться по дорогам за счет полного кругового обзора. Кроме того, беспилотные автомобили будут обмениваться этой информацией с соседними автомобилями, что поможет им эффективно маневрировать, например, в составе колонны.

Такой уровень взаимодействия опирается на скорость и надежность. Например, в сценарии, требующем экстренного торможения всехавтомобилей, находящихся в одно время на данном участке дороги, система беспилотного вождения должна послать мгновенное предупреждение движущимся сзади автомобилям, чтобы предотвратить групповое столкновение. Такое предупреждение будет эффективным лишь в том случае, если оно вовремя достигнет автомобилей сзади и позволит им выполнить маневр уклонения.

Технологии 5G обеспечивают скорость и надежность, необходимую беспилотным автомобилям. Один из наиболее популярных способов применения 5G - сверхнадежные системы связи с малыми задержками (Ultra-Reliable LowLatency Communication, URLLC), обеспечивающие гарантированную задержку не более 1 мс и надежность 99,999\%. Беспилотным автомобилям, полностью зависимым от возможности взаимодействия с окружающими автомобилями, эта технология просто необходима.

\section{БЕСПРОВОДНЫЕ ЧИПСЕТЫ ДЛЯ БЕСПИЛОТНЫХ АВТОМОБИЛЕЙ}

Перед инженерами, проектирующими чипсеты для беспилотных автомобилей, внедрение технологий 5С ставит новые задачи, при этом требуется разрабатывать новые 
гибкие математические алгоритмы, устройства миллиметрового диапазона, системы с несколькими входами/выходами (МІмO) и решать проблемы формирования диаграммы направленности. Комбинация этих технологий, требования к тестированию устройств 5 С по радиоэфиру (ОТА), большие потери распространения в миллиметровом диапазоне и специфические проблемы, связанные с чипсетами для автомобилей (например, применение автомобильных антенн), дополнительно усложняют проектирование чипсетов для беспилотных автомобилей.

Например, на качество сигнала оказывают влияние многие факторы, такие как обработка модулирующего сигнала, модуляция, фильтрация и повышающее преобразование частоты. Сигналы в электронных системах беспилотных автомобилей подвержены искажениям, которые особенно заметны на высоких частотах в более широких каналах, свойственных миллиметровому диапазону.

Системы с ортогональным частотным разделением каналов (OFDM) способны предотвращать помехи, вызванные наложением поднесущих. Однако искажения модулированного сигнала могут порождаться такими проблемами, как синфазные/квадратурные (I/Q) помехи, фазовый шум, линейные (АМ в АМ) и нелинейные (АМ в ФМ) преобразования и погрешность частоты. Наиболее важным фактором в системах OFDM миллиметрового диапазона является фазовый шум. Избыточный фазовый шум приводит к недопустимому увеличению модуля вектора ошибки, что вносит искажения в процесс демодуляции. Кроме того, избыточный фазовый шум порождает помехи поднесущих, что тоже отрицательно влияет на демодуляцию.

Переход в миллиметровый диапазон позволяет расширить полосу канала, но порождает новые проблемы, связанные с потерями и блокировками при распространении сигнала. Из-за короткой длины волны физические объекты, в том числе и другие автомобили, препятствуют распространению сигнала, что дополнительно усугубляется конструкцией автомобильных антенн.

Ключевой технологией, используемой для решения проблем распространения в миллиметровом диапазоне, является формирование диаграммы направленности - метод, который заключается в подаче на каждый антенный элемент сигнала определенной фазы и амплитуды для формирования луча в заданном направлении. В результате передача в миллиметровом диапазоне имеет узконаправленный характер и требует применения активных антенн с большим усилением с электрически формируемой диаграммой направленности. В автомобильных системах, где корпус автомобиля действует как большая заземленная плоскость, расположенная в непосредственной близости от антенны, миллиметровое излучение создает массу дополнительных проблем для тестирования и усложняет управление бюджетом канала.

Разработчикам чипсетов для беспилотныхавтомобилей приходится преодолевать физические проблемы, связанные с особенностями сигналов миллиметрового диапазона. Поэтому применяемые контрольно-измерительные решения должны точно измерять и оценивать характеристики сигнала, не порождая новых проблем.

\section{ЛИТЕРАТУРА}

1. Three in Four Americans Remain Afraid of Fully SelfDriving Vehicles. - https://newsroom.aaa.com/2019/03/ americans-fear-self-driving-cars-survey/

2. SAE International Releases Updated Visual Chart for Its "Levels of Driving Automation" Standard for Self-Driving Vehicles. - https://www.sae.org/news/ press-room/2018/12/sae-international-releasesupdated-visual-chart-for-its-\%E2\%80\% 9Clevels-ofdriving-automation\%E2\%80\%9D-standard-for-selfdriving-vehicles

\section{КНИГИ ИЗДАТЕЛЬСТВА "ТЕХНОСФЕРА"}

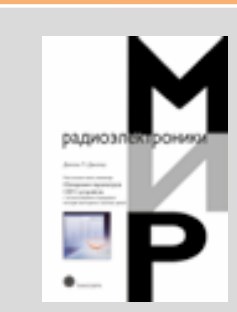

Цена 1600 руб.

\section{НАСТОЛЬНАЯ КНИГА ИНЖЕНЕРА} ИЗМЕРЕНИЯ ПАРАМЕТРОВ СВЧ-УСТРОЙСТВ С ИСПОЛЬЗОВАНИЕМ ПЕРЕДОВЫХ МЕТОДИК ВЕКТОРНОГО АНАЛИЗА ЦЕПЕЙ Дансмор Джоэль П.

Издание осуществлено при поддержке компании Keysight Technologies Пер. с англ. и науч. ред. Е. Ю.Харитонова, Е. В.Андронова, А. С. Бондаренко

Автор книги - инженер-разработчик векторных анализаторов цепей с более чем тридцатилетним стажем, работал над широчайшим кругом измерительных задач в СВЧ-диапазоне - от компонентов сотового телефона до спутниковых мүльтиплексоров. Задача этой книги - передать читателю знания и опыт автора, чтобы инженеры смогли повысить качество и эффективность выполнения научноисследовательских и конструкторских работ, а также облегчить работу инженеров-метрологов.

\section{КАК ЗАКАЗАТЬ НАШИ КНИГИ?}

$凶$ 125319, Москва, а/я 91; + +7 495 234-0110; \$ +7 495 956-3346; knigi@technosphera.ru, sales@technosphera.ru 